\title{
Biofilm matrix of Candida albicans and Candida tropicalis: chemical composition and role in drug resistance
}

\author{
Mohammed A. Al-Fattani and L. Julia Douglas \\ Division of Infection and Immunity, Institute of Biomedical and Life Sciences, Joseph Black \\ Building, University of Glasgow, Glasgow G12 800, UK
}

Correspondence

L. Julia Douglas

J.Douglas@bio.gla.ac.uk

Received 9 February 2006

Accepted 18 April 2006

\begin{abstract}
Matrix material was extracted from biofilms of Candida albicans and Candida tropicalis and analysed chemically. Both preparations contained carbohydrate, protein, hexosamine, phosphorus and uronic acid. However, the major component in C. albicans matrix was glucose (32\%), whereas in C. tropicalis matrix it was hexosamine (27\%). Biofilms of C. albicans were more easily detached from plastic surfaces by treatment with the enzyme lyticase $(\beta-1,3-$ glucanase $)$ than were those of $C$. tropicalis. Biofilms of $C$. albicans were also partially detached by treatment with proteinase $\mathrm{K}$, chitinase, $\mathrm{DNase} \mathrm{I}$, or $\beta$ - $N$-acetylglucosaminidase, whereas $\mathrm{C}$. tropicalis biofilms were only affected by lipase type VII or chitinase. To investigate a possible role for the matrix in biofilm resistance to antifungal agents, biofilms of $C$. albicans were grown under conditions of continuous flow in a modified Robbins device (MRD). These biofilms produced more matrix material than those grown statically, and were significantly more resistant to amphotericin B. Biofilms of C. tropicalis synthesized large amounts of matrix material even when grown statically, and such biofilms were completely resistant to both amphotericin $B$ and fluconazole. Mixed-species biofilms of C. albicans and a slime-producing strain of Staphylococcus epidermidis (RP62A), when grown statically or in the MRD, were also completely resistant to amphotericin B and fluconazole.

Mixed-species biofilms of C. albicans and a slime-negative mutant of S. epidermidis (M7), on the other hand, were completely drug resistant only when grown under flow conditions. These results demonstrate that the matrix can make a significant contribution to drug resistance in Candida biofilms, especially under conditions similar to those found in catheter infections in vivo, and that the composition of the matrix material is an important determinant in resistance.
\end{abstract}

\section{INTRODUCTION}

Candida albicans and a small number of related Candida species are known to be important agents of hospitalacquired infections. Many of these are implant-associated infections in which the micro-organisms form adherent biofilms on the surfaces of catheters, joint replacements, prosthetic heart valves and other medical devices (Donlan, 2001; Douglas, 2003). Candida septicaemias, for example, now rank as the fourth most common type of nosocomial bloodstream infection and are usually catheter-related (Calderone, 2002). Biofilm cells on implants are organized into structured communities embedded within a matrix of extracellular material. They are phenotypically distinct from planktonic or suspended cells; in particular, they are significantly less susceptible to antimicrobial agents (Donlan \& Costerton, 2002; Gilbert et al., 2002). As a result, implant

Abbreviations: MRD, modified Robbins device; PIA, intercellular polysaccharide adhesin; SEM, scanning electron microscopy; XTT, 2,3bis(2-methoxy-4-nitro-5-sulfophenyl)-2H-tetrazolium-5-carboxanilide. infections are difficult to treat and usually the implant must be removed (Costerton et al., 1999).

The matrix is one of the most distinctive features of a microbial biofilm. It forms a three-dimensional, gel-like, highly hydrated and locally charged environment in which the micro-organisms are largely immobilized (Flemming et al., 2000). Matrix-enclosed microcolonies, sometimes described as 'stacks' or 'towers', are separated by water channels which provide a mechanism for nutrient circulation within the biofilm (Donlan \& Costerton, 2002). The composition of the matrix varies according to the nature of the organisms present. Matrix polymers of bacterial biofilms are primarily exopolysaccharides, and many are negatively charged due to the presence of carboxyl, sulphate or phosphate groups. Smaller amounts of proteins, nucleic acids and lipids can also be present. Two of the bestcharacterized matrix polysaccharides in bacteria are alginate (a polymer of mannuronic acid and guluronic acid) produced by Pseudomonas aeruginosa, and poly $\beta$-1,6-linked $N$-acetylglucosamine secreted by Staphylococcus epidermidis 
and Staphylococcus aureus (Starkey et al., 2004; Gotz, 2002). Synthesis of both polysaccharides has been related to bacterial virulence.

The recalcitrance of biofilms to antimicrobial agents is often attributed to the failure of these agents to penetrate the biofilm matrix. However, a number of studies have demonstrated that reductions in the diffusion coefficients of antibiotics within biofilms are insufficient to account solely for the observed changes in susceptibility (Gilbert et al., 2002). Drug access is also assisted by the presence of water channels in the biofilm structure. Nevertheless, matrix components could retard access to such an extent that cells lying deep within a microcolony escape exposure. This would occur via drug adsorption or neutralization, and would depend on the thickness of the biofilm and on the chemical nature of both the antimicrobial agent and the matrix material. It is known, for example, that fluoroquinolones penetrate $P$. aeruginosa biofilms readily, whereas penetration by positively charged aminoglycosides is retarded (Drenkard, 2003). Similarly, fluconazole permeates single-species Candida biofilms more rapidly than flucytosine (Al-Fattani \& Douglas, 2004). Rates of drug diffusion through biofilms of Candida glabrata or Candida krusei are faster than those through biofilms of Candida parapsilosis or Candida tropicalis, while drug diffusion through mixed-species biofilms of $C$. albicans and $S$. epidermidis is very slow.

During a previous investigation in this laboratory, the matrix of C. albicans biofilms was isolated and its composition compared with that of extracellular polymeric material obtained from culture supernatants of planktonically grown organisms (Baillie \& Douglas, 2000). Both preparations contained carbohydrate, protein, phosphorus and hexosamine, but the matrix had significantly less carbohydrate $(41 \%)$ and protein $(5 \%)$. It also had a higher proportion of glucose $(16 \%)$ than mannose, unlike planktonic extracellular material (McCourtie \& Douglas, 1985). To investigate whether the matrix plays a role in the resistance of biofilms to antifungal agents, susceptibility profiles of biofilms incubated statically (which have relatively little matrix) were compared with those of biofilms incubated with gentle shaking (which produce much more matrix material). Biofilms grown with or without shaking did not exhibit significant differences in susceptibility to any of the drugs tested, suggesting that drug resistance is unrelated to the extent of matrix formation (Baillie \& Douglas, 2000). On the other hand, earlier studies with a perfused biofilm fermenter (Baillie \& Douglas, 1998a) and a cylindrical filter model system (Baillie \& Douglas, 1998b) showed that resuspended biofilm cells (which presumably had lost most of their matrix) were some $20 \%$ less resistant to amphotericin B than intact C. albicans biofilms, indicating that the matrix could have a contributory role in drug resistance. These findings with resuspended biofilm cells were subsequently confirmed elsewhere (Ramage et al., 2002).
In the study described here, we have isolated and chemically analysed matrix material from biofilms of both C. albicans and C. tropicalis. Further characterization of matrix composition was achieved by enzymic digestion of biofilms. In a series of experiments designed to investigate biofilm drug resistance, Candida biofilms were grown statically and under flow conditions in a modified Robbins device (MRD) to model catheter infections; the susceptibilities of both types of biofilm to antifungal agents were then tested. Mixed-species biofilms of C. albicans and S. epidermidis were also assayed for antifungal susceptibility after growth under the same static and flow conditions. S. epidermidis is the organism most frequently isolated from bacterial implant infections and has been found in polymicrobial infections with C. albicans (Jenkinson \& Douglas, 2002).

\section{METHODS}

Organisms. Two Candida species were used in this study. C. albicans GDH 2346 (NCYC 1467) was originally isolated at Glasgow Dental Hospital from a patient with denture stomatitis. C. tropicalis AAHB 73 was isolated from a patient with a line infection at Crosshouse Hospital, Kilmarnock, Scotland. Both strains were maintained on slopes of Sabouraud dextrose agar (Difco) and subcultured monthly. Every 2 months, cultures were replaced by new ones freshly grown from freeze-dried stocks.

Two strains of S. epidermidis (RP62A and M7) were maintained on Colombia blood agar (Oxoid). Strain RP62A (ATCC 35984) is a known slime producer; strain M7 is a slime-negative mutant obtained after chemical mutagenesis of $S$. epidermidis RP62A with mitomycin C (Schumacher-Perdreau et al., 1994). The growth rate, initial adherence, cell-wall composition, surface characteristics and antimicrobialsusceptibility profile of strain M7 are indistinguishable from those of the wild-type (Schumacher-Perdreau et al., 1994).

Medium and culture conditions. Both Candida species were grown in yeast nitrogen base (YNB) medium (Difco) containing $50 \mathrm{mM}$ glucose. Batches of medium $(50 \mathrm{ml}$, in $250 \mathrm{ml}$ Erlenmeyer flasks) were inoculated from fresh slopes and incubated at $37^{\circ} \mathrm{C}$ for $24 \mathrm{~h}$ in an orbital shaker at 60 r.p.m. Cells were harvested and washed twice in $0 \cdot 15 \mathrm{M}$ PBS, $\mathrm{pH} 7 \cdot 2$. Before use in biofilm experiments, all washed cell suspensions were adjusted to $\mathrm{OD}_{520} 0 \cdot 8$.

Tryptic soy broth (Difco) was selected as the liquid medium best able to support the growth of both fungi and bacteria. C. albicans GDH 2346 and the two strains of S. epidermidis (RP62A and M7) grow at similar rates in this medium (Adam et al., 2002). Cultures were inoculated from fresh slopes and incubated with shaking at $37^{\circ} \mathrm{C}$ for $24 \mathrm{~h}$. Cells were harvested, washed twice in PBS and suspended to $\mathrm{OD}_{520} 0 \cdot 8$ prior to use in biofilm experiments. For mixed-species biofilms, equal volumes of the standardized suspension of each organism were mixed immediately before use.

Isolation of matrix material. Biofilms grown for the extraction of matrix material were formed on sections (4 cm long) of polyvinyl chloride (PVC) Faucher tubes (French gauge 36; Vygon) that had been cut into three equal concave strips. The strips were sterilized by exposure to ultraviolet radiation for $15 \mathrm{~min}$ on each side. Standardized cell suspension was added to the concave surface of each strip, and the strips were incubated for $1 \mathrm{~h}$ at $37^{\circ} \mathrm{C}$. After removal of non-adherent cells by washing, the strips were transferred to wide-neck $250 \mathrm{ml}$ Erlenmeyer flasks (six strips per flask) 
containing YNB $(50 \mathrm{ml})$ with $50 \mathrm{mM}$ glucose. They were then incubated at $37^{\circ} \mathrm{C}$ for $48 \mathrm{~h}$ in an orbital shaker operating at 60 r.p.m. for biofilm formation.

Biofilm matrix material was isolated using a slight modification of a protocol described previously (Baillie \& Douglas, 2000). Catheter strips with their adherent biofilms were transferred to universal bottles (six strips per bottle) each containing $10 \mathrm{ml}$ distilled water. The bottles were sonicated for $5 \mathrm{~min}$ in an ultrasonic water bath and vortexed vigorously for $1 \mathrm{~min}$ to disrupt the biofilms. Cell suspensions were then pooled and centrifuged. The supernatants were concentrated to one-tenth of the original volume using an Amicon DC2 hollow-fibre system with a $3.0 \mathrm{kDa}$ molecular weight cut-off filter (Millipore) and dialysed at $4{ }^{\circ} \mathrm{C}$ for 3 days $(3.5 \mathrm{kDa}$ molecular weight cut-off dialysis membrane; Pierce) against five changes ( 1 each) of distilled water. The retentates were freeze-dried.

Chemical analysis of matrix material. Protein was determined by the Lowry method, phosphorus by the method of Chen et al. (1956), and uronic acid by the method of Bitter \& Muir (1962). Total carbohydrate was estimated according to the procedure of Dubois et al. (1956), using glucose as a standard. Glucose content was determined enzymically using a glucose oxidase/peroxidase assay kit (Sigma) after hydrolysis of samples in $0.5 \mathrm{M} \mathrm{HCl}$ at $100{ }^{\circ} \mathrm{C}$ for $5 \mathrm{~h}$. Hexosamine was estimated by the method of Blumenkrantz \& Asboe-Hansen (1976) using glucosamine as a standard; before analysis, samples were hydrolysed in $4 \mathrm{M} \mathrm{HCl}$ at $100^{\circ} \mathrm{C}$ for $12 \mathrm{~h}$.

Enzymic detachment of biofilms. Eight enzymes (all from Sigma) were tested for their ability to detach Candida biofilms from plastic surfaces. The enzymes used were: proteinase $\mathrm{K}$ extracted from Tritirachium album; protease type XIV from Streptomyces griseus; deoxyribonuclease 1 type IV from bovine pancreas; $\mathrm{N}$-acetylglucosaminidase from Canavalia ensiformis (Jack bean); chitinase from Strep. griseus; lipase type VII from Candida rugosa; phospholipase A2 from bovine pancreas; and lyticase from Arthrobacter luteus. All enzyme solutions were prepared immediately before use. Proteinase $\mathrm{K}$, protease type XIV and lyticase were in $\mathrm{Na}_{2} \mathrm{HPO}_{4} / \mathrm{NaH}_{2} \mathrm{PO}_{4}$ buffer, $\mathrm{pH} 7 \cdot 5$; deoxyribonuclease 1 type IV and $\mathrm{N}$-acetylglucosaminidase were in citric acid $/ \mathrm{Na}_{2} \mathrm{HPO}_{4}$ buffer, $\mathrm{pH} 5 \cdot 0$; lipase type VII was in $\mathrm{Na}_{2} \mathrm{HPO}_{4} / \mathrm{NaH}_{2} \mathrm{PO}_{4}$ buffer, $\mathrm{pH} 7 \cdot 2$; phospholipase A2 was in Tris/maleate $/ \mathrm{NaOH}$ buffer, $\mathrm{pH} 8 \cdot 0$; and chitinase was in citric acid/ $\mathrm{Na}_{2} \mathrm{HPO}_{4}$ buffer, $\mathrm{pH} 6 \cdot 0$.

The detachment assay used was based on that reported by Kaplan et al. (2004) for S. epidermidis biofilms. Aliquots $(100 \mu \mathrm{l})$ of standardized Candida cell suspension were added to the wells of 96-well polystyrene microtitre plates, and the plates were incubated at $37^{\circ} \mathrm{C}$ for $48 \mathrm{~h}$ to allow biofilm formation. The growth medium was removed from each well and replaced by an equal volume $(100 \mu \mathrm{l})$ of test enzyme used at a final concentration of $50 \mu \mathrm{g} \mathrm{ml}^{-1}$. Control wells received an equal volume of buffer without enzyme. Plates were incubated for $2 \mathrm{~h}$ at 25 or $37^{\circ} \mathrm{C}$ according to the temperature optimum for the enzyme being tested. Following incubation, biofilms were stained with crystal violet ( $2 \mathrm{~g}$ crystal violet, $0.8 \mathrm{~g}$ ammonium oxalate, and $20 \mathrm{ml}$ ethanol per $100 \mathrm{ml}$ ) for $2 \mathrm{~min}$, and then twice washed gently with $200 \mu \mathrm{l}$ distilled water and left to dry. The optical densities of the wells were determined with a Bio-Rad Benchmark microplate reader set to $570 \mathrm{~nm}$.

Biofilm formation under static conditions on PVC catheter disks. Biofilms were formed on small disks (diameter, $0.8 \mathrm{~cm}$ ) cut from PVC Faucher tubes (French gauge 36; Vygon), as described previously (Hawser \& Douglas, 1994; Baillie \& Douglas, 1999). Sterile disks were placed in wells of 24-well Nunclon tissue culture plates, and $80 \mu \mathrm{l}$ of standardized cell suspension was added to each one. After incubation for $1 \mathrm{~h}$ at $37^{\circ} \mathrm{C}$ (adhesion period), nonadherent organisms were removed by washing with PBS. The disks were then incubated in the wells of fresh plates containing $1 \mathrm{ml}$ YNB with $50 \mathrm{mM}$ glucose, or $1 \mathrm{ml} \mathrm{TSB}$, for $48 \mathrm{~h}$ at $37^{\circ} \mathrm{C}$ for biofilm formation.

Biofilm formation under flow conditions using the MRD. The MRD is one of the most widely used systems for studying biofilm growth under conditions of continuous flow. It is an artificial multiport sampling catheter, constructed of a perspex block, $41.5 \mathrm{~cm}$ long, with a rectangular lumen containing 25 evenly spaced sample ports (Lappin-Scott et al., 1993). The sample studs, also made of perspex, fit tightly into the ports. Each stud has at its bottom end a $1 \mathrm{~mm}$ rim into which a catheter disk can be inserted. During incubation, biofilms are formed on these disks and can be removed aseptically by simply taking out the sample studs.

In the experiments described here, a reservoir containing a standardized suspension of the test organism(s) was connected to a peristaltic pump and the MRD via silicone tubing. The entire apparatus was incubated at $37^{\circ} \mathrm{C}$. Cell suspension was pumped through the MRD at a flow rate of $60 \mathrm{ml} \mathrm{h}^{-1}$ for $1 \mathrm{~h}$ to allow cells to adhere to each of the 25 catheter disks attached to the sample studs. Upon leaving the $\mathrm{MRD}$, the cell suspension was collected in an effluent container. Fresh growth medium (either YNB with $50 \mathrm{mM}$ glucose, or TSB) was then continuously pumped through the MRD at the same flow rate for $48 \mathrm{~h}$. After this time, biofilms formed on the catheter disks could be retrieved by removing the sample studs from the MRD. Following the completion of each experiment, the MRD was sterilized with $0.05 \%$ hibitane, which was pumped through at $60 \mathrm{ml} \mathrm{h}^{-1}$ for $1 \mathrm{~h}$. Sterile distilled water was finally pumped through at a rate of $200 \mathrm{ml} \mathrm{h}^{-1}$ for $1 \mathrm{~h}$ to remove any traces of hibitane.

Susceptibility of biofilms to antifungal agents. After growth under static or flow conditions, Candida biofilms and Candidal Staphylococcus biofilms were treated with amphotericin B (Sigma) or fluconazole (Pfizer) by a procedure described earlier (Hawser \& Douglas, 1995; Adam et al., 2002). Freshly prepared stock solutions of the drugs were diluted in growth medium (YNB with $50 \mathrm{mM}$ glucose, or TSB) buffered to $\mathrm{pH} 7$ with $0 \cdot 165 \mathrm{M}$ MOPS buffer (Sigma). Biofilms $(48 \mathrm{~h})$ grown statically or under flow conditions on catheter disks were transferred to wells of 24-well Nunclon plates containing $1 \mathrm{ml}$ of this buffered medium with the test antifungal agent, and incubated for 5 or $24 \mathrm{~h}$ at $37^{\circ} \mathrm{C}$. Two different concentrations of amphotericin $\mathrm{B}\left(6 \cdot 5\right.$ and $39 \mu \mathrm{g} \mathrm{ml}^{-1} ; 5$ and 30 times the MIC) were used for biofilms of C. albicans GDH 2346. Biofilms of C. tropicalis AAHB 73 and Candida/Staphylococcus biofilms were treated with a single concentration of amphotericin B and fluconazole (39 and $12 \mu \mathrm{g} \mathrm{ml}^{-1}$, respectively; 30 times the MIC for C. albicans GDH 2346). Following the drug treatment, biofilms were washed in PBS and biofilm activity was assessed by the 2,3-bis(2-methoxy-4nitro-5-sulfophenyl)-2H-tetrazolium-5-carboxanilide (XTT) reduction assay (Baillie \& Douglas, 1999; Adam et al., 2002) after transfer of the disks to new wells. The effect of an antifungal agent was measured in terms of XTT reduction by biofilms as compared with values obtained for control biofilms incubated for $5 \mathrm{~h}$ in the absence of the agent.

Scanning electron microscopy (SEM). Biofilms were examined by SEM after processing of samples by a freeze-drying technique (Hawser et al., 1998; Baillie \& Douglas, 1999), which gives improved preservation of the biofilm matrix. Biofilms formed on catheter disks were fixed with glutaraldehyde $(2 \cdot 5 \%, \mathrm{v} / \mathrm{v}$, in $0 \cdot 1 \mathrm{M}$ cacodylate buffer, $\mathrm{pH} 7 \cdot 0$ ), washed gently three times in distilled water, and then plunged into a liquid propane/isopentane mixture $(2: 1, \mathrm{v} / \mathrm{v})$ at $-196^{\circ} \mathrm{C}$ before freeze-drying under vacuum $\left(10^{-6}\right.$ torr, $\left.1 \cdot 3 \times 10^{-4} \mathrm{~Pa}\right)$. Samples were finally coated with gold with a Polaron coater and viewed under a Philips 500 scanning electron microscope. 


\section{RESULTS AND DISCUSSION}

\section{Isolation of matrix material from Candida biofilms}

Matrix material was prepared from biofilms of two different Candida species, C. albicans GDH 2346 and C. tropicalis AAHB 73. There is no standard extraction procedure for biofilm matrix, and a variety of physical and chemical extractions have been reported (Liu \& Fang, 2002; Azeredo et al., 1999). Many of these methods promote leakage of intracellular material (Azeredo et al., 1999). In this study, a physical extraction process was used in an attempt to minimize leakage. This involved gentle sonication, vortexing and centrifugation of biofilms formed on sections of catheter tubing. Two separate preparative procedures were carried out for each organism to provide sufficient material for chemical analysis. The yield from biofilms of $C$. tropicalis $(16.5$ and $23.6 \mathrm{mg}$ ) was much higher than that from biofilms of C. albicans $(10 \cdot 7$ and $9 \cdot 4 \mathrm{mg})$.

\section{Chemical composition of the biofilm matrix}

Preparations of biofilm matrix material were analysed for carbohydrate, glucose, protein, hexosamine, phosphorus and uronic acid by colorimetric or enzymic methods. Matrix isolated from C. albicans biofilms consisted of carbohydrate (39.6\%, including $32 \cdot 2 \%$ glucose), together with small amounts of protein $(5 \cdot 0 \%)$, hexosamine $(3.3 \%)$, phosphorus $(0 \cdot 5 \%)$ and uronic acid $(0 \cdot 1 \%$; Table 1$)$. These values largely confirm those reported in an earlier analysis from this laboratory which also revealed the presence of small amounts of mannose and galactose in the matrix (Baillie \& Douglas, 2000). Both studies demonstrate that glucose is the major sugar component of C. albicans matrix material. However, glucose accounted for a larger proportion of the matrix dry weight in the present investigation. This could be due to a difference in the growth medium:

Table 1. Analysis of matrix material extracted from biofilms of C. albicans GDH 2346 and C. tropicalis AAHB 73

The data are mean \pm SEM for two independent experiments (with two different matrix preparations) carried out in duplicate or triplicate.

\begin{tabular}{|lcc|}
\hline Component & Percentage composition of biofilm matrix for: \\
\cline { 2 - 3 } & C. albicans & C. tropicalis \\
\hline Carbohydrate & $39 \cdot 6 \pm 0 \cdot 3$ & $3 \cdot 3 \pm 0 \cdot 0$ \\
Glucose & $32 \cdot 2 \pm 1 \cdot 5$ & $0 \cdot 5 \pm 0 \cdot 0$ \\
Hexosamine & $3 \cdot 3 \pm 0 \cdot 6$ & $27 \cdot 4 \pm 0 \cdot 2$ \\
Phosphorus & $0 \cdot 5 \pm 0 \cdot 0$ & $0 \cdot 2 \pm 0 \cdot 0$ \\
Protein & $5 \cdot 0 \pm 0 \cdot 1$ & $3 \cdot 3 \pm 0 \cdot 0$ \\
Uronic acid & $0 \cdot 1 \pm 0 \cdot 0$ & $1 \cdot 6 \pm 0 \cdot 0$ \\
\hline
\end{tabular}

galactose was used as the carbon source in the previous study but was replaced here by glucose.

By contrast, matrix from C. tropicalis biofilms consisted mainly of hexosamine $(27 \cdot 4 \%)$, with smaller amounts of carbohydrate $(3.3 \%$, including $0.5 \%$ glucose), protein $(3 \cdot 3 \%)$ and phosphorus $(0 \cdot 2 \%$; Table 1$)$. The C. tropicalis matrix also contained slightly more uronic acid $(1.6 \%)$ than that of $C$. albicans. The major difference between the two preparations, however, was that in C. tropicalis, hexosamine appeared to replace glucose as the main identifiable sugar component in the matrix (Table 1). As far as we are aware, this is the first reported analysis of the biofilm matrix of $C$. tropicalis. However, a number of bacteria are known to produce similarly large amounts of hexosamine as a matrix component. The best-studied example is S. epidermidis, in which hexosamine is present as a polysaccharide of $\beta$-1,6-linked $N$-acetylglucosamine residues containing some deacetylated amino groups, and succinate and phosphate substituents (Mack et al., 1996). This polymer, which is sometimes referred to as the intercellular polysaccharide adhesin (PIA), mediates cell-cell interaction within the biofilm (Gotz, 2002) and its production has been related to S. epidermidis virulence in catheter-infection models in animals.

\section{Enzymic detachment of Candida biofilms}

An assay devised by Kaplan et al. (2004) for S. epidermidis biofilms was used to investigate whether Candida biofilms could be enzymically detached from plastic surfaces by degradation of the matrix polymers. A range of commercially available enzymes of known specificity was tested. Biofilms were grown in the wells of 96-well polystyrene microtitre plates and then treated with different test enzymes at 37 or $25^{\circ} \mathrm{C}$ (according to the temperature optimum) for $2 \mathrm{~h}$ at a final enzyme concentration of $50 \mu \mathrm{g} \mathrm{ml}^{-1}$. After washing, the remaining organisms were stained with crystal violet and the $\mathrm{OD}_{570}$ measured using a microtitre plate reader.

Biofilms of C. albicans were unaffected by lipase type VII, phospholipase A2 and protease type XIV (Table 2). Treatment with proteinase $\mathrm{K}$, chitinase, DNase I or $\beta-N$ acetylglucosaminidase resulted in a significant decrease in $\mathrm{OD}_{570}$, suggesting that these enzymes partially degraded matrix material and caused some biofilm detachment from the surfaces of the wells. Interestingly, lyticase, which hydrolyses $\beta-1,3$ glucan, had by far the greatest effect, causing an $85 \%$ reduction in optical density $(P<0.001$; Table 2$)$. This result suggests that some of the glucose present in the $C$. albicans matrix could be present as $\beta-1,3$ glucan, a polysaccharide which is also a major structural component of the cell wall.

Biofilms of $C$. tropicalis responded rather differently to the enzyme treatments. Phospholipase A2, protease type XIV, proteinase $\mathrm{K}$, DNase I and $\beta$ - $N$-acetylglucosaminidase had no significant effect (Table 2). By contrast, treatment with 
Table 2. Detachment of Candida biofilms after exposure to different test enzymes

\begin{tabular}{|lcc|}
\hline Enzyme $^{\star}$ & \multicolumn{1}{c|}{ Biofilm OD $_{\mathbf{5 7 0}}$ as a percentage of control value $\dagger$} \\
\cline { 2 - 3 } & C. albicans & C. tropicalis \\
\hline Lipase type VII & $100 \cdot 0 \pm 5 \cdot 6$ & $73 \cdot 9 \pm 1 \cdot 9 \ddagger$ \\
Phospholipase A2 & $100 \cdot 0 \pm 3 \cdot 7$ & $92 \cdot 2 \pm 2 \cdot 5$ \\
Protease type XIV & $100 \cdot 0 \pm 4 \cdot 9$ & $88 \cdot 3 \pm 5 \cdot 4$ \\
Proteinase K & $69 \cdot 2 \pm 2 \cdot 8 \ddagger$ & $93 \cdot 1 \pm 5 \cdot 8$ \\
Chitinase & $77 \cdot 2 \pm 4 \cdot 7 \ddagger$ & $71 \cdot 3 \pm 3 \cdot 5 \ddagger$ \\
DNase I & $70 \cdot 8 \pm 4 \cdot 4 \ddagger$ & $100 \cdot 0 \pm 2 \cdot 2$ \\
Lyticase & $15 \cdot 4 \pm 1 \cdot 2 \$$ & $46 \cdot 2 \pm 2 \cdot 2 \$$ \\
$\beta$ - $N$-Acetylglucosaminidase & $79 \cdot 3 \pm 2 \cdot 6 \ddagger$ & $94 \cdot 9 \pm 2 \cdot 6$ \\
\hline
\end{tabular}

${ }^{*}$ All enzyme treatments were carried out for $2 \mathrm{~h}$ at 37 or $25^{\circ} \mathrm{C}$ with a final enzyme concentration of $50 \mu \mathrm{g} \mathrm{ml}^{-1}$.

$\dagger$ The data are mean \pm SEM of two independent experiments each carried out twice with 36 replicates for every enzyme tested. Control $\mathrm{OD}_{570}$ values ranged from $0 \cdot 119 \pm 0 \cdot 01$ to $0 \cdot 169 \pm 0 \cdot 01$ for C. albicans biofilms, and from $0 \cdot 274 \pm 0 \cdot 02$ to $0 \cdot 319 \pm 0 \cdot 01$ for C. tropicalis biofilms.

$\ddagger$ Value significantly different at $P<0.05$ from that for the control.

§Value significantly different at $P<0.001$ from that for the control.

lipase type VII and chitinase did appear to produce some biofilm detachment $(P<0 \cdot 05)$. Chitinase had a similar effect on biofilms of both $C$. tropicalis and $C$. albicans, indicating that most of the hexosamine present in the $C$. tropicalis matrix was unlikely to be in the form of chitin. It could, instead, be in the form of a chitinase-resistant $\beta$-1,6-linked polysaccharide like that found in $S$. epidermidis and other biofilm-forming bacteria. The greatest effect on $C$. tropicalis biofilms was again observed with lyticase, which caused a reduction in optical density of over $53 \%(P<0.001$; Table 2). However, lyticase had less effect on these biofilms than on those of C. albicans, whose matrix material contains substantially more glucose (Table 1).

Possible lysis of biofilm cells during their exposure to lyticase was investigated by resuspending the cells after enzyme treatment in $1 \mathrm{M}$ sorbitol buffer, and comparing the optical density with that of suspensions of control (untreated) biofilm cells. With C. albicans, exposure to lyticase reduced the optical density readings of the suspensions, suggesting that there could have been some cell lysis during the enzyme treatment (results not shown). Alternatively, the reduction in optical density could simply have been due to dissolution of some of the matrix material. The latter explanation seems more likely, since suspensions of $C$. tropicalis showed no such reduction, even though lyticase is known to induce protoplast formation with this organism ( $\mathrm{Su} \&$ Meyer, 1991).

DNA is now known to be a major matrix component in some bacterial biofilms (Starkey et al., 2004). DNase I had no effect on C. tropicalis biofilms, but did cause some detachment of $C$. albicans biofilms. The presence of DNA in the $C$. albicans matrix would be consistent with the higher phosphorus content of the matrix of this organism (Table 1). Biofilms of C. tropicalis, but not those of C. albicans, were partially detached by treatment with lipase type VII, but both were resistant to the action of phospholipase A2. In this context, it is interesting that C. tropicalis is capable of producing a fibrillar layer that contains mannoprotein with covalently linked fatty acids (Kappeli \& Fiechter, 1977; Kappeli et al., 1984).

\section{SEM of biofilms grown statically and under conditions of continuous flow}

The model system used for static biofilm culture involved the growth of adherent populations for $48 \mathrm{~h}$ on the surface of small disks cut from catheters. This model has been well characterized and is known to give reproducible biofilm populations (Hawser \& Douglas, 1994; Baillie \& Douglas, 1999). To produce flow conditions, an MRD was used.

SEM showed that biofilms formed by $C$. albicans incubated statically on catheter disks consisted of a dense network of yeasts, germ tubes, hyphae and pseudohyphae. As reported previously (Hawser et al., 1998), relatively little matrix material was visible in these biofilms, even when samples were prepared using a freeze-drying technique that gives improved preservation of the matrix. However, biofilms grown in the MRD under flow conditions had an extensive matrix as revealed by SEM (Fig. 1A). This confirmed earlier findings which demonstrate that biofilms subjected to a liquid flow produce substantially more matrix material than those incubated statically (Hawser et al., 1998). In contrast with $C$. albicans, biofilms of C. tropicalis synthesized large amounts of extracellular material even during 

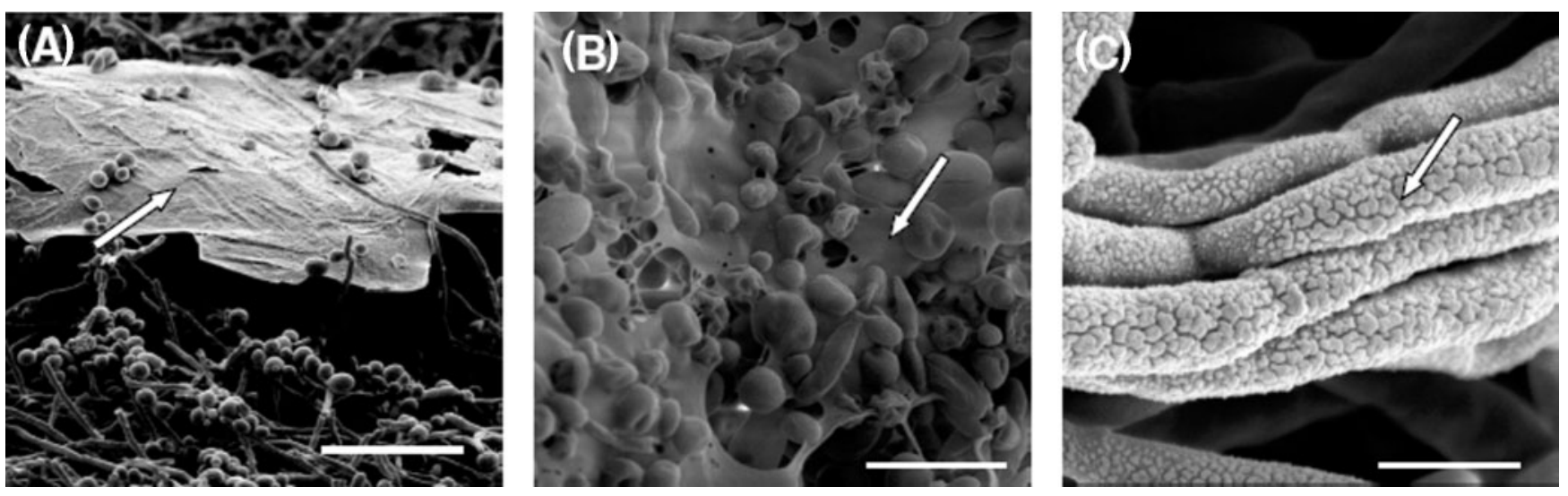

Fig. 1. Scanning electron micrographs of biofilm formation by $C$. albicans $(A)$ and $C$. tropicalis (B, C) on PVC catheter disks. Biofilms were incubated under flow conditions in the MRD (A), or statically $(B, C)$, for $48 \mathrm{~h}$ in YNB medium containing $50 \mathrm{mM}$ glucose. Arrows indicate matrix material. Bars, $20 \mu \mathrm{m}(\mathrm{A}) ; 10 \mu \mathrm{m}(\mathrm{B}) ; 2 \mu \mathrm{m}(\mathrm{C})$.

growth under static conditions, and many of the cells were almost hidden by the enveloping matrix (Fig. 1B). At high magnification, matrix material was clearly visible on the surface of the cells (Fig. 1C).

\section{Drug susceptibility of biofilms grown under static or flow conditions}

Biofilms of C. albicans grown under static and flow conditions were exposed to different concentrations of amphotericin $\mathrm{B}$ at $37^{\circ} \mathrm{C}$ for 5 or $24 \mathrm{~h}$. After incubation, the metabolic activity of the biofilms, as measured by XTT reduction, was compared with that of control biofilms incubated in the absence of the drug (Table 3). C. albicans biofilms grown under flow conditions were highly resistant to amphotericin B at a concentration five times the MIC; exposure for $24 \mathrm{~h}$ had no effect on metabolic activity. At an even higher drug concentration (30 times the MIC), with a shorter exposure time $(5 \mathrm{~h})$, the biofilms were rather less resistant. However, for both drug treatments, biofilms formed under flow conditions were significantly more resistant than those grown statically (Table 3 ). These results differ from those obtained in a previous study in which flow conditions were achieved by gentle shaking of biofilms during incubation, a procedure which promotes the synthesis of matrix material (Hawser et al., 1998). Biofilms grown with or without shaking did not exhibit significant differences in susceptibility to flucytosine, fluconazole or amphotericin B (Baillie \& Douglas, 2000). A possible explanation for this is that the shaking procedure, which produced conditions of turbulent flow, was less effective at stimulating matrix synthesis than the laminar flow system provided by the MRD. The morphology and physical properties of some bacterial biofilms are strongly influenced by the magnitude of the shear stresses under which the biofilms are formed (Stoodley et al., 2000). Our present results with C. albicans indicate that a constant flow $\left(60 \mathrm{ml} \mathrm{h}^{-1}\right)$ of liquid across the developing biofilm promotes matrix synthesis to an extent that significantly enhances resistance to amphotericin $\mathrm{B}$.

Table 3. Effect of amphotericin B on C. albicans GDH 2346 biofilms grown under static and flow conditions

\begin{tabular}{|c|c|c|c|c|}
\hline \multirow[t]{3}{*}{ Drug treatment ${ }^{\star}$} & \multicolumn{4}{|c|}{ XTT formazan formation $\dagger$} \\
\hline & \multicolumn{2}{|c|}{ Static conditions $\ddagger$} & \multicolumn{2}{|c|}{ Flow conditions $\ddagger$} \\
\hline & $\mathrm{OD}_{492}$ & Percentage of control & $\mathrm{OD}_{492}$ & Percentage of control \\
\hline $5 \times \operatorname{MIC}(24 \mathrm{~h})$ & $1 \cdot 19 \pm 0 \cdot 03$ & $60 \cdot 7 \pm 1 \cdot 30$ & $2 \cdot 95 \pm 0 \cdot 04$ & $99 \cdot 4 \pm 1 \cdot 2$ \\
\hline $30 \times \operatorname{MIC}(5 \mathrm{~h})$ & $0 \cdot 94 \pm 0 \cdot 00$ & $39 \cdot 6 \pm 0 \cdot 10$ & $1 \cdot 62 \pm 0 \cdot 22$ & $54 \cdot 6 \pm 7 \cdot 4$ \\
\hline
\end{tabular}

${ }^{\star}$ Biofilms were treated with amphotericin B at five times MIC for $24 \mathrm{~h}$ or 30 times MIC for $5 \mathrm{~h}$.

$\dagger$ The data are mean \pm SEM of two independent experiments carried out in quadruplicate.

$\ddagger$ Results for biofilms grown statically were significantly different from those for biofilms grown under flow conditions $(P<0 \cdot 001)$. 
Attempts to grow biofilms of $C$. tropicalis AAHB 73 under flow conditions in the MRD were unsuccessful. This organism grew on, and rapidly blocked, the silicone tubing leading to the device, apparently by producing large amounts of slime. Biofilms of $C$. tropicalis grown statically were totally resistant to the action of both amphotericin $\mathrm{B}$ and fluconazole when exposed to high concentrations of the drugs for either 5 or $24 \mathrm{~h}$ (Table 4). Rates of drug diffusion through statically grown Candida biofilms have been determined recently using a filter disk assay (Al-Fattani \& Douglas, 2004). Of several Candida species and strains tested, the slowest penetration was observed with $C$. tropicalis AAHB 73. In view of our analytical data on matrix preparations (Table 1), this suggests that drug resistance could be affected not only by the overall extent of matrix formation but also by its composition. Biofilms of C. tropicalis, with an extensive, hexosamine-rich matrix, were poorly penetrated by antifungal agents. On the other hand, biofilms of $C$. albicans, with a less-extensive glucoserich matrix, were more readily penetrated by drugs. Several reports indicate that in bacteria, possession of a mucoid phenotype is associated with decreased susceptibility to antibiotics. For example, biofilms of a mucoid clinical isolate of $P$. aeruginosa are substantially less susceptible to the quinolone antibiotic ciprofloxacin than biofilms of a non-mucoid isolate (Evans et al., 1991). Similarly, biofilms produced by an alginate-overproducing strain of $P$. aeruginosa exhibit a highly structured architecture and are significantly more resistant to tobramycin than biofilms formed by an isogenic non-mucoid strain (Hentzer et al., 2001).

\section{Drug susceptibility of mixed fungal/bacterial biofilms grown under static and flow conditions}

Previous work with statically grown C. albicans biofilms has indicated that the presence of bacteria (S. epidermidis) can enhance biofilm resistance to antifungal agents (Adam et al.,
2002). In this study, the drug susceptibility of mixed fungal/ bacterial biofilms grown under static and flow conditions was compared. As before, two strains of $S$. epidermidis were used: a slime-producing wild-type (RP62A) and a slimenegative mutant (M7). Strain RP62A produces the intercellular adhesin PIA; M7 is a mutant of strain RP62A that also produces PIA but lacks a $140 \mathrm{kDa}$ antigen termed accumulation-associated protein (Hussain et al., 1997; Gotz, 2002). The mutant is able to form biofilms on PVC disks (Adam et al., 2002), although it was originally reported as being unable to accumulate on glass surfaces (SchumacherPerdreau et al., 1994). However, the extent of biofilm formation (or production of matrix material) by the mutant is less than that of the wild-type strain, as judged by both SEM and quantitative assays (Adam et al., 2002). The M7 mutant is also more easily eradicated in vitro and in animal models by various antibiotics than is the wild-type strain (Schwank et al., 1998).

Mixed-species biofilms of C. albicans and S. epidermidis RP62A grown statically, or under flow conditions in the MRD, were highly resistant to both amphotericin $B$ and fluconazole (Table 5). At exposure times of 5 and $24 \mathrm{~h}$, the drugs had no effect on the metabolic activity of the biofilms, despite the high drug concentration used (30 times MIC). Moreover, biofilms produced statically were just as resistant as those grown under flow conditions (Table 5). These results contrast with those obtained for single-species $C$. albicans biofilms treated with amphotericin $\mathrm{B}$, for which biofilms grown statically were more susceptible to the drug (Table 3). They suggest that the slime produced by S. epidermidis RP62A might partially protect C. albicans from amphotericin $B$ in these statically grown, mixedspecies biofilms. Preparations of matrix material (slime) from clinical isolates of $S$. epidermidis have been shown to reduce the efficacy of some antibiotics when mixed with the drugs in zone-of-inhibition bioassays (Souli \& Giamarellou, 1998). Similar results were obtained when staphylococcal

Table 4. Effect of amphotericin B and fluconazole on biofilms of C. tropicalis AAHB 73

ND, Not determined.

\begin{tabular}{|lccc|}
\hline Antifungal agent & \multicolumn{3}{c|}{ XTT formazan formation $\dagger$} \\
\cline { 2 - 3 } & \multicolumn{2}{c|}{ Static conditions $\ddagger$} & Flow conditions \\
\cline { 2 - 4 } & OD $_{\mathbf{4 9 2}}$ & Percentage of control & \\
\hline Amphotericin B (5 h) & $1 \cdot 98 \pm 0 \cdot 04$ & $109 \cdot 7 \pm 2 \cdot 4$ & ND \\
Amphotericin B (24 h) & $1 \cdot 92 \pm 0 \cdot 06$ & $104 \cdot 7 \pm 3 \cdot 4$ & ND \\
Fluconazole (5 h) & $1 \cdot 92 \pm 0 \cdot 08$ & $106 \cdot 5 \pm 4 \cdot 7$ & ND \\
Fluconazole (24 h) & $1 \cdot 86 \pm 0 \cdot 06$ & $101 \cdot 8 \pm 3 \cdot 3$ & ND \\
\hline
\end{tabular}

${ }^{\star}$ Amphotericin $\mathrm{B}$ was used at a concentration of $39 \mu \mathrm{g} \mathrm{ml}^{-1}$ and fluconazole at $12 \mu \mathrm{g} \mathrm{ml}{ }^{-1}$. Exposure to each drug was for 5 or $24 \mathrm{~h}$.

$\dagger$ The data are mean \pm SEM of two independent experiments carried out in quadruplicate.

$\ddagger$ Results not significantly different from those of the controls $(P>0 \cdot 05)$. 
Table 5. Effect of amphotericin B and fluconazole on mixed-species biofilms of C. albicans GDH 2346 and S. epidermidis RP62A grown under static or flow conditions

\begin{tabular}{|c|c|c|c|c|}
\hline \multirow[t]{3}{*}{ Antifungal agent ${ }^{*}$} & \multicolumn{4}{|c|}{ XTT formazan formation $\dagger$} \\
\hline & \multicolumn{2}{|c|}{ Static conditions $\ddagger$} & \multicolumn{2}{|c|}{ Flow conditions $\ddagger$} \\
\hline & $\mathrm{OD}_{492}$ & Percentage of control & $\mathrm{OD}_{492}$ & Percentage of control \\
\hline Amphotericin B (5 h) & $2 \cdot 86 \pm 0 \cdot 03$ & $98 \cdot 9 \pm 1 \cdot 0$ & $2 \cdot 31 \pm 0 \cdot 16$ & $105 \cdot 8 \pm 7 \cdot 3$ \\
\hline Amphotericin B (24 h) & $2 \cdot 87 \pm 0 \cdot 05$ & $99 \cdot 8 \pm 1 \cdot 7$ & $2 \cdot 97 \pm 0 \cdot 06$ & $93 \cdot 2 \pm 1 \cdot 9$ \\
\hline Fluconazole $(5 \mathrm{~h})$ & $2 \cdot 76 \pm 0 \cdot 06$ & $95 \cdot 5 \pm 2 \cdot 1$ & $2 \cdot 18 \pm 0 \cdot 06$ & $100 \cdot 1 \pm 2 \cdot 8$ \\
\hline Fluconazole (24 h) & $2 \cdot 95 \pm 0 \cdot 02$ & $102 \cdot 4 \pm 0 \cdot 7$ & $3 \cdot 04 \pm 0 \cdot 06$ & $95 \cdot 3 \pm 1 \cdot 9$ \\
\hline
\end{tabular}

${ }^{\star}$ The concentrations of the two drugs used in this assay were equivalent (30 times MIC). Exposure to each drug was for 5 or $24 \mathrm{~h}$.

$\dagger$ The data are mean \pm SEM of two independent experiments carried out in quadruplicate.

$\ddagger$ Results not significantly different $(P>0.05)$ for biofilms grown under static and flow conditions with identical drug treatments.

slime was mixed with planktonic bacteria in susceptibility testing using a broth-dilution method (Konig et al., 2001). However, attempts to correlate the hydrophobicity or charge of each antibiotic tested with loss of activity due to the slime were unsuccessful (Souli \& Giamarellou, 1998).

Mixed-species biofilms containing the slime-negative mutant M7 grown under flow conditions were highly resistant to amphotericin B and fluconazole at both exposure times ( 5 and $24 \mathrm{~h}$ ), despite the high drug concentration used (30 times MIC; Table 6). They were, however, slightly less resistant than biofilms containing the slime-producing S. epidermidis RP62A treated in the same way (Table 5). For both drug treatments, mixed-species biofilms containing M7 and developed under static conditions were significantly more susceptible than those grown under conditions of continuous flow. The difference was particularly marked for biofilms treated with fluconazole (Table 6). These findings suggest that under flow conditions, enhanced production of matrix material by either C. albicans or M7, or both organisms, might afford some protection against antifungal agents.

Overall, our results indicate that drug resistance of $C$. albicans biofilms may be significantly enhanced by increased production of matrix material under flow conditions in the MRD, or by the presence of one or more matrix polymers of $S$. epidermidis in mixed-species biofilms. Biofilms of C. tropicalis, on the other hand, are less susceptible to antifungal agents than $C$. albicans biofilms, even when grown statically, possibly due to the synthesis of a hexosamine-containing matrix polymer similar to $S$. epidermidis PIA. Drug diffusion through C. albicans/S. epidermidis biofilms grown statically on cellulose filters is slower than that through C. albicans biofilms or even $C$.

Table 6. Effect of amphotericin B and fluconazole on mixed-species biofilms of C. albicans GDH 2346 and S. epidermidis M7 grown under static or flow conditions

\begin{tabular}{|c|c|c|c|c|}
\hline \multirow[t]{3}{*}{ Antifungal agent ${ }^{\star}$} & \multicolumn{4}{|c|}{ XTT formazan formation $\dagger$} \\
\hline & \multicolumn{2}{|c|}{ Static conditions $\ddagger$} & \multicolumn{2}{|c|}{ Flow conditions $\ddagger$} \\
\hline & $\mathrm{OD}_{492}$ & Percentage of control & $\mathrm{OD}_{492}$ & Percentage of control \\
\hline Amphotericin B (5 h) & $2 \cdot 05 \pm 0 \cdot 03$ & $88 \cdot 7 \pm 1 \cdot 3$ & $2 \cdot 73 \pm 0 \cdot 01$ & $99 \cdot 0 \pm 0 \cdot 4$ \\
\hline Amphotericin B (24 h) & $1.69 \pm 0.09$ & $71 \cdot 8 \pm 3 \cdot 8$ & $2 \cdot 94 \pm 0 \cdot 09$ & $91 \cdot 9 \pm 2 \cdot 8$ \\
\hline Fluconazole $(5 \mathrm{~h})$ & $1 \cdot 53 \pm 0 \cdot 07$ & $66 \cdot 4 \pm 3 \cdot 0$ & $2 \cdot 58 \pm 0 \cdot 11$ & $93 \cdot 5 \pm 3 \cdot 9$ \\
\hline Fluconazole (24 h) & $1 \cdot 59 \pm 0 \cdot 11$ & $67 \cdot 2 \pm 4 \cdot 6$ & $2 \cdot 92 \pm 0 \cdot 04$ & $91 \cdot 5 \pm 1 \cdot 3$ \\
\hline
\end{tabular}

${ }^{\star}$ The concentrations of the two drugs used in this assay were equivalent (30 times MIC). Exposure to each drug was for 5 or $24 \mathrm{~h}$.

$\dagger$ The data are mean \pm SEM of two independent experiments carried out in quadruplicate.

$\ddagger$ Results are significantly different at $P<0.01$ for biofilms grown under static and flow conditions with identical drug treatments. 
tropicalis biofilms (Al-Fattani \& Douglas, 2004). Interactions between different matrix polymers in these mixedspecies biofilms could produce a more viscous matrix. Such a finding was reported by Skillman et al. (1999) during a study of Enterobacter agglomerans/Klebsiella pneumoniae biofilms; increased matrix viscosity was advanced as a possible explanation for enhanced resistance to disinfection. Similarly, rheological interactions between matrix polysaccharides from Pseudomonas (now Burkholderia) cepacia and $P$. aeruginosa have been shown to decrease the rates of diffusion and antimicrobial activities of antibiotics (Allison \& Matthews, 1992). Clearly, matrix polymers do contribute towards drug resistance in both single-species and mixedspecies biofilms containing Candida, especially under the flow conditions which prevail in many implant infections. However, biofilm resistance overall is likely to be multifactorial, involving, in addition, drug-resistant physiologies such as dormant 'quiescent' cells and expression of efflux pumps (Gilbert et al., 2002).

\section{ACKNOWLEDGEMENTS}

M. A. A.-F. is the recipient of a research studentship from the Ministry of Health, Saudi Arabia. We are indebted to Margaret Mullin for expert assistance with electron microscopy.

\section{REFERENCES}

Adam, B., Baillie, G. S. \& Douglas, L. J. (2002). Mixed species biofilms of Candida albicans and Staphylococcus epidermidis. J Med Microbiol 51, 344-349.

Al-Fattani, M. A. \& Douglas, L. J. (2004). Penetration of Candida biofilms by antifungal agents. Antimicrob Agents Chemother 48, 3291-3297.

Allison, D. G. \& Matthews, M. J. (1992). Effect of polysaccharide interactions on antibiotic susceptibility of Pseudomonas aeruginosa. J Appl Bacteriol 73, 484-488.

Azeredo, J., Lazarova, V. \& Oliveira, R. (1999). Methods to extract the exopolymeric matrix from biofilms: a comparative study. Wat Sci Tech 39, 243-250.

Baillie, G. S. \& Douglas, L. J. (1998a). Effect of growth rate on resistance of Candida albicans biofilms to antifungal agents. Antimicrob Agents Chemother 42, 1900-1905.

Baillie, G. S. \& Douglas, L. J. (1998b). Iron-limited biofilms of Candida albicans and their susceptibility to amphotericin B. Antimicrob Agents Chemother 42, 2146-2149.

Baillie, G. S. \& Douglas, L. J. (1999). Candida biofilms and their susceptibility to antifungal agents. Methods Enzymol 310, 644-656.

Baillie, G. S. \& Douglas, L. J. (2000). Matrix polymers of Candida biofilms and their possible role in biofilm resistance to antifungal agents. J Antimicrob Chemother 46, 397-403.

Bitter, T. \& Muir, H. M. (1962). A modified uronic acid carbazole reaction. Anal Biochem 4, 330-334.

Blumenkrantz, N. \& Asboe-Hansen, E. (1976). An assay for total hexosamine and a differential assay for glucosamine and galactosamine. Clin Biochem 9, 269-274.

Calderone, R. A. (2002). Candida and Candidiasis. Washington, DC: American Society for Microbiology.
Chen, P. S., Toribara, T. Y. \& Warner, H. (1956). Microdetermination of phosphorus. Anal Chem 28, 1756-1758.

Costerton, J. W., Stewart, P. S. \& Greenberg, E. P. (1999). Bacterial biofilms: a common cause of persistent infections. Science 284, 1318-1322.

Donlan, R. M. (2001). Biofilms and device-associated infections. Emerg Infect Dis 7, 277-281.

Donlan, R. M. \& Costerton, J. W. (2002). Biofilms: survival mechanisms of clinically relevant microorganisms. Clin Microbiol Rev 15, 167-193.

Douglas, L. J. (2003). Candida biofilms and their role in infection. Trends Microbiol 11, 30-36.

Drenkard, E. (2003). Antimicrobial resistance of Pseudomonas aeruginosa biofilms. Microbes Infect 5, 1213-1219.

Dubois, M., Gilles, K. A., Hamilton, J. K., Rebers, P. A. \& Smith, F. (1956). Colorimetric method for determination of sugars and related substances. Anal Chem 28, 350-356.

Evans, D. J., Allison, D. G., Brown, M. R. W. \& Gilbert, P. (1991). Susceptibility of Pseudomonas aeruginosa and Escherichia coli biofilms towards ciprofloxacin: effect of specific growth rate. J Antimicrob Chemother 27, 177-184.

Flemming, H.-C., Wingender, J., Mayer, C., Korstgens, V. \& Borchard, W. (2000). Cohesiveness in biofilm matrix polymers. In Community Structure and Co-operation in Biofilms, pp. 87-105. Edited by D. G. Allison, P. Gilbert, H. M. Lappin-Scott \& M. Wilson. Cambridge: Cambridge University Press.

Gilbert, P., Maira-Litran, T., McBain, A. J., Rickard, A. H. \& Whyte, F. W. (2002). The physiology and collective recalcitrance of microbial biofilm communities. Adv Microb Physiol 46, 203-256.

Gotz, F. (2002). Staphylococcus and biofilms. Mol Microbiol 43, 1367-1378.

Hawser, S. P. \& Douglas, L. J. (1994). Biofilm formation by Candida species on the surface of catheter materials in vitro. Infect Immun $\mathbf{6 2}$, 915-921.

Hawser, S. P. \& Douglas, L. J. (1995). Resistance of Candida albicans biofilms to antifungal agents in vitro. Antimicrob Agents Chemother 39, 2128-2131.

Hawser, S. P., Baillie, G. S. \& Douglas, L. J. (1998). Production of extracellular matrix by Candida albicans biofilms. J Med Microbiol 47, 253-256.

Hentzer, M., Teitzel, G. M., Balzer, G. J., Heydorn, A., Molin, S., Givskov, M. \& Parsek, M. R. (2001). Alginate overproduction affects Pseudomonas aeruginosa biofilm structure and function. J Bacteriol 183, 5395-5401.

Hussain, M., Herrman, M., von Eiff, C., Perdreau-Remington, F. \& Peters, G. (1997). A 140-kilodalton extracellular protein is essential for the accumulation of Staphylococcus epidermidis strains on surfaces. Infect Immun 65, 519-524.

Jenkinson, H. F. \& Douglas, L. J. (2002). Interactions between Candida species and bacteria in mixed infections. In Polymicrobial Diseases, pp. 357-373. Edited by K. A. Brogden \& J. M. Guthmiller. Washington, DC: American Society for Microbiology.

Kaplan, J. B., Ragunath, C., Velliyagounder, K., Fine, D. H. \& Ramasubbu, N. (2004). Enzymatic detachment of Staphylococcus epidermidis biofilms. Antimicrob Agents Chemother 48, 2633-2636.

Kappeli, O. \& Fiechter, A. (1977). Component from the cell surface of the hydrocarbon-utilizing yeast Candida tropicalis with possible relation to hydrocarbon transport. J Bacteriol 131, 917-921.

Kappeli, O., Walther, P., Mueller, M. \& Fiechter, A. (1984). Structure of the cell surface of the yeast Candida tropicalis and its relation to hydrocarbon transport. Arch Microbiol 138, 279-282. 
Konig, C., Schwank, S. \& Blaser, J. (2001). Factors compromising antibiotic activity against biofilms of Staphylococcus epidermidis. Eur J Clin Microbiol Infect Dis 20, 20-26.

Lappin-Scott, H. M., Jass, J. \& Costerton, J. W. (1993). Microbial biofilm formation and characterization. In Microbial Biofilms: Formation and Control, pp. 1-12. Edited by S. P. Denyer, S. P. Gorman \& M. Sussman. Oxford: Blackwell.

Liu, H. \& Fang, H. H. P. (2002). Extraction of extracellular polymeric substances (EPS) of sludges. J Biotechnol 95, 249-256.

Mack, D., Fischer, W., Krokotsch, A., Leopold, K., Hartmann, R., Egge, H. \& Laufs, R. (1996). The intercellular adhesin involved in biofilm accumulation of Staphylococcus epidermidis is a linear $\beta-1$, 6-linked glucoaminoglycan: purification and structural analysis. J Bacteriol 178, 175-183.

McCourtie, J. \& Douglas, L. J. (1985). Extracellular polymer of Candida albicans: isolation, analysis and role in adhesion. J Gen Microbiol 131, 495-503.

Ramage, G., Bachmann, S., Patterson, T. F., Wickes, B. L. \& LopezRibot, J. L. (2002). Investigation of multidrug efflux pumps in relation to fluconazole resistance in Candida albicans biofilms. J Antimicrob Chemother 49, 973-980.

Schumacher-Perdreau, F., Heilmann, C., Peters, G., Gotz, F. \& Pulverer, G. (1994). Comparative analysis of a biofilm-forming Staphylococcus epidermidis strain and its adhesion-positive, accumulation-negative mutant M7. FEMS Microbiol Lett 117, 71-78.
Schwank, S., Rajacic, Z., Zimmerli, W. \& Blaser, J. (1998). Impact of bacterial biofilm formation on in vitro and in vivo activities of antibiotics. Antimicrob Agents Chemother 42, 895-898.

Skillman, L. C., Sutherland, I. W. \& Jones, M. V. (1999). The role of exopolysaccharides in dual species biofilm development. J Appl Microbiol Symp Suppl 48, 13S-18S.

Souli, M. \& Giamarellou, H. (1998). Effects of slime produced by clinical isolates of coagulase-negative staphylococci on activities of various antimicrobial agents. Antimicrob Agents Chemother 42, 939-941.

Starkey, M., Gray, K. A., Chang, S. I. \& Parsek, M. R. (2004). A sticky business: the extracellular polymeric substance matrix of bacterial biofilms. In Microbial Biofilms, pp. 174-191. Edited by M. Ghannoum \& G. A. O’Toole. Washington, DC: American Society for Microbiology.

Stoodley, P., Hall-Stoodley, L., Boyle, J. D., Jorgensen, F. \& Lappin-Scott, H. M. (2000). Environmental and genetic factors influencing biofilm structure. In Community Structure and Cooperation in Biofilms, pp. 54-64. Edited by D. G. Allison, P. Gilbert, H. M. Lappin-Scott \& M. Wilson. Cambridge: Cambridge University Press.

Su, C. S. \& Meyer, S. A. (1991). Characterization of mitochondrial DNA in various Candida species: isolation, restriction endonuclease analysis, and base composition. Int J Syst Bacteriol 41, 6-14. 